\title{
CONVERSION OF ETHANOL TO OLEFINS OVER HZSM-5 CATALYSTS
}

\author{
P. R. S. SALBEGO* ${ }^{* 1}$, G. S. N. M. CENTENARO ${ }^{1}$, R. KLAIC ${ }^{1}$, N. I. CANABARRO ${ }^{1}$, T. K. \\ MULLER $^{1}$, M. A. MAZUTTI ${ }^{1}$, E. L. FOLETTO ${ }^{1}$, S. L. JAHN ${ }^{1}$ \\ ${ }^{1}$ Universidade Federal de Santa Maria, Departamento de Engenharia Química. \\ *paulosalbego@gmail.com
}

\begin{abstract}
This work aims the synthesis and study of ZSM-5 catalysts for the conversion of ethanol to light olefins, especially, using an alternative and inexpensive route. The ethanol emerges as a renewable source for the production of olefins. The ZSM5 catalyst has important characteristics for this type of reaction such as acidity, surface area and particle size. The synthesis was carried out in hydrothermal treatment at $170{ }^{\circ} \mathrm{C}$. Were performed two synthesis with templates, using n-butylamine and tetrapropylammonium hydroxide (TPAOH), and an alternative and novel way using a nucleating gel. The catalyst characterization was performed using several techniques (XRD, BET, SEM and TGA). The catalytic reaction studied the influence of temperature (250 to $450{ }^{\circ} \mathrm{C}$ ) and $\mathrm{SAR}\left(\mathrm{Si} / \mathrm{Al}_{2}\right.$ ratio). The products analysis was made with a gas chromatograph. The ethylene yield was above to $80 \%$ for all catalysts. Lower SAR values obtain higher yields for propylene, around to $8 \%$. The temperature, SAR and template influenced in the selectivity. The nucleating gel method showed to be a viable and inexpensive alternative for ZSM-5 synthesis.
\end{abstract}

\section{INTRODUCTION}

Nowadays, light olefins are in a growing demand since are used as feedstock for several polymeric products, and its production is manly as a byproduct of naphtha steam cracking and catalytic cracking of crude oil (Meng et al. 2012; Ouyang et al. 2009). The environmental issue regarding this type of process have made several researchers to explore for alternative and sustainable routes for olefins production, and following this tendency, ethanol show as a potential candidate for feedstock, in the ethanol to olefins (ETO) reaction (Inaba et al. 2007; Lu and Liu 2011).

The use of ZSM-5 zeolite as catalyst for conversion of ethanol to light olefins become an option because of its characteristics such as acidity, structure and shape-selective. The textural properties of ZSM-5 zeolite, especially its framework $\mathrm{Si} / \mathrm{Al}$, which is related to the acidity of the catalyst, played a vital role in determining the nature of the product. In the ZSM-5 synthesis, templates are used for more structural stability and this substances can be neutral or charged, organic or inorganic and are used to induce crystallization and assist to define the structure (Fouad et al. 2006; Sang et al. 2004). 


\section{9 a 22 de outubro de 2014 \\ Florianópolis/SC}

With the importance of find new methods for ZSM-5 synthesis, some studies are trying routes without the aid of templates (Cheng et al. 2008; Kalipçilar et al. 2007), and one of the synthesis in this work use a small portion of template in a attempt to find a alternative and inexpensive route for the ZSM-5 synthesis and consequently to the ETO reaction.

Thus, the aim of this work was study and evaluate HZSM-5 catalysts for the ETO reaction. For that reason, catalysts where synthesized in two traditional methods with the aid of templates with the purpose of comparing with an a third and novel way using a nucleating gel containing a small concentration of template (Lam et al. 2006), all with three different SAR ( $\mathrm{Si} / \mathrm{Al}_{2}$ ratio) values (30, 60 and 100). In addition to that was studied, in the catalyst activity, the influence of the reaction temperature $\left(250\right.$ to $\left.450^{\circ} \mathrm{C}\right)$.

\section{EXPERIMENTAL}

\subsection{Catalyst Preparation}

The ZSM-5 zeolites were synthesized hydrothermally. Water glass $\left(\mathrm{Na}_{2} \mathrm{SiO}_{3}\right.$, Sigma Aldrich, $\left.53.0 \% \mathrm{Na}_{2} \mathrm{O}, 47.0 \% \mathrm{SiO}_{2}\right)$, Fumed Silica $\left(\mathrm{SiO}_{2}\right.$, Sigma Aldrich, $\left.0.2-0.3 \mu \mathrm{m}\right)$ were used as $\mathrm{Si}$ source and aluminum sulfate $\left(\mathrm{Al}_{2}\left(\mathrm{SO}_{4}\right)_{3}\right.$, Sigma Aldrich) as Al source. Concentrated sulfuric acid $\left(\mathrm{H}_{2} \mathrm{SO}_{4}, 95.0 \%\right.$, Vetec) was applied to adjust the $\mathrm{OH}^{-} / \mathrm{Si}$ ratio $(0.25)$ from the synthesis gel for all methods. The ZSM-5 catalyst were synthesized in three different process, two traditional ways using TPAOH and n-butylamine as template and the third and alternative way using a nucleating gel with a small amount of TPAOH in its composition with short reaction time, only $12 \mathrm{~h}$. All the synthesis methods were made in three different SAR values (30,60 and 100).

The general synthesis process for the two first methods was using the following procedures: Template, water, water glass and fumed silica were mixed to get solution A. Fumed silica was used as a way to adjust the silica amount of each synthesis. Aluminum sulfate was dissolved in water to get solution $\mathrm{B}$, and then concentrated $\mathrm{H}_{2} \mathrm{SO}_{4}$ was added. Solution $\mathrm{B}$ was added to solution A with mechanical stirring. After the addition was completed, the gel was stirred for 15 min to get a homogenous gel, and then was transferred to a stainless-steel autoclave and placed in an air oven maintained at $170{ }^{\circ} \mathrm{C}(60$ hours with $\mathrm{TPAOH}$ and $50 \mathrm{~h}$ with n-butylamine). After the reaction, the obtained products (NaZSM-5) were washed with deionized water until the $\mathrm{pH}$ value of the washing water reached 7 , and then dried overnight at $110{ }^{\circ} \mathrm{C}$.

The synthesis conditions for the method using TPAOH was following Argauer and Landolt (1972), and with n-butylamine was based in the method of Rubin et al. (1979). The third method, via nucleating gel was the same from the two first mentioned above, only with the addition of the gel instead of the template in the solution $\mathrm{A}$ and a reaction time of only $12 \mathrm{~h}$. The nucleating gel was prepared as reported by Lam et al. (2006).

The removal of organic template was carried out at $550{ }^{\circ} \mathrm{C}$ for $6 \mathrm{~h}$ in a muffle furnace. In order to obtain the acidic form (HZSM-5), an ion exchange was carried with a $1 \mathrm{M} \mathrm{NH}_{4} \mathrm{Cl}$ solution at $80{ }^{\circ} \mathrm{C}$ for $2 \mathrm{~h}$, the process was repeated 2 times each one followed with a filtration, the products were dried 


\section{9 a 22 de outubro de 2014 \\ Florianópolis/SC}

at $110{ }^{\circ} \mathrm{C}$ overnight. The dry products were heated at $500{ }^{\circ} \mathrm{C}$ for $5 \mathrm{~h}$ in a muffle furnace to give the $\mathrm{H}$ form products, the samples were crushed and sieved in a 50 mesh sieve. The catalysts were named according to its template, TPAOH and n-butylamine as $\mathrm{ZT}$ and $\mathrm{ZB}$, respectively. The ZSM-5 synthesized via nucleating gel as ZG. All followed by its SAR, e.g., ZT30 for the synthesis using TPAOH with SAR 30.

\subsection{Catalyst Characterization}

The X-ray diffraction (XRD) patterns was obtained using a Rigaku MiniFlex 300 diffractometer operating with $\mathrm{Cu} \mathrm{K \alpha}(\lambda=1.54051 \AA ; 30 \mathrm{kV}$ and $10 \mathrm{~mA})$. The patterns were recorded over the $2 \theta$ angle ranging from 5 to $50^{\circ}$ at a step size of $0.03^{\circ}$ and an acquisition time of $0.9 \mathrm{~s}$.

The crystal morphology was observed using a scanning electron microscopy (SEM) JEOL JSM 6060. Nitrogen adsorption/desorption isotherms at $-196{ }^{\circ} \mathrm{C}$ was obtained after outgassing the sample under vacuum at $150{ }^{\circ} \mathrm{C}$ for $4 \mathrm{~h}$, using a Micromeritics ASAP 2020 adsorption apparatus. The BET (Brunauer-Emmett-Teller) method was used to obtain the surface area. The micropore area and volume were obtained by the t-plot method.

Thermogravimetric analysis was carried out on a TGA Q5000 (TA Instruments Inc., USA) in order to confirm the template presence and the ionic exchange $\left(\mathrm{NH}_{4}\right)$. The heating rate was $10{ }^{\circ} \mathrm{C}$ $\mathrm{min}^{-1}$, the $\mathrm{N}_{2}$ flow rate was $50 \mathrm{~cm}^{3} \mathrm{~min}^{-1}$, with the temperature ranging from 40 to $900{ }^{\circ} \mathrm{C}$. The sample mass was 4 to $10 \mathrm{mg}$. The TGA equipment was calibrated using $\mathrm{CaC}_{2} \mathrm{O}_{4} \mathrm{H}_{2} \mathrm{O}(99.9 \%)$.

\subsection{Reaction Procedure}

The catalytic reaction tests were carried out in a continuous fixed-bed flow reactor (A "U" shape glass reactor with an inner diameter of $4 \mathrm{~mm}$ ) under atmospheric pressure, using a vaporized EtOH-N ${ }_{2}$ flow, and the change in catalytic performance trough out the reaction was analyzed. Ethanol $\left(95.0 \%\right.$, Vetec) was used as received, and the flow was controlled using a Mass-Flo ${ }^{\circledR}$ Controller MKS. The temperature of the catalyst fixed in the reactor was raised to the reaction temperature using $\mathrm{N}_{2}$ as carrier gas. The products were analyzed by a gas chromatograph (Shimadzu, CG-17A) that were directly connected to the reactor, using a HP-PLOT-Q (Agilent Technologies) column and an FIDtype detector.

All the catalysts were pretreated at $200{ }^{\circ} \mathrm{C}$ for 1 hour $\left(\mathrm{N}_{2}\right.$ flow rate set at $\left.60 \mathrm{~cm}^{3} \mathrm{~min}^{-1}\right)$ prior the reaction to eliminate possible water adsorbed in the surface of the catalyst. The weight of catalyst used was $0,025 \mathrm{~g}$. The reaction gas was obtained by mixing $\mathrm{N}_{2}$ and vaporized ethanol $\left(23{ }^{\circ} \mathrm{C}\right)$, with a $\mathrm{N}_{2}$ flow rate set at $100 \mathrm{~cm}^{3} \mathrm{~min}^{-1}$. To avoid possible condensation of ethanol, the temperature of the effluent line was constantly maintained at $120{ }^{\circ} \mathrm{C}$. The reaction temperature was increased stepwise $\left(50{ }^{\circ} \mathrm{C}\right.$ ) from 250 to $450{ }^{\circ} \mathrm{C}$ and maintained at each temperature for $40 \mathrm{~min}$. The yield of each product was defined as the conversion of ethanol to the products, and the selectivity to each product was defined as its yield divided by the total conversion of ethanol. 


\section{RESULTS AND DISCUSSION}

\subsection{HZSM-5 Synthesis}

Thermogravimetric analysis were carried out with the purpose of confirm the presence of template in the samples, especially the traditional routes (ZT and $\mathrm{ZB}$ ) and also verify if the ionic change was accomplished. The prepared HZSM-5 had a well-defined ZSM-5 zeolite structure, as indicated by their XRD patterns (Fig. 1). There were no diffraction peaks other than those of the ZSM-5 zeolite. In general, samples with SAR 30 had a large surface area and a well defined structure.

The ZT and ZB had well-defined ZSM-5 samples in all SAR studied. In other hand, the ZG samples had a large difference in the structure, as we can see in the XRD, an increase in crystallinity is observed from the compound with SAR 100 to 30 , since the ZG had a synthesis method with a very short quantity of template, where the amount of aluminum is the major responsible for the compound crystallization, than the samples with SAR 30 had a large surface area and a well defined structure and the compounds with larger SAR had a amorphous structure (Fig. 1c) and with shorter surface area because of its large particle size (Table 1).

Table 1 - Physical properties of synthesized ZSM-5.

\begin{tabular}{cccc}
\hline Catalyst & $\mathbf{S}_{\mathbf{B E T}}{ }^{\mathbf{a}}\left(\mathbf{m}^{\mathbf{2}} \mathbf{g}^{-\mathbf{1}}\right)$ & $\mathbf{S}_{\text {micro }}{ }^{\mathbf{b}}\left(\mathbf{m}^{\mathbf{2}} \mathbf{g}^{-\mathbf{1}}\right)$ & $\mathbf{V}_{\text {micro }}{ }^{\mathbf{c}}\left(\mathbf{c m}^{\mathbf{3}} \mathbf{g}^{-\mathbf{1}}\right)$ \\
\hline ZT30 & 370.51 & 292.10 & 0.14 \\
ZT60 & 346.17 & 227.38 & 0.11 \\
ZT100 & 383.81 & 257.31 & 0.12 \\
ZB30 & 380.08 & 271.49 & 0.12 \\
ZB60 & 308.18 & 217.70 & 0.10 \\
ZB100 & 283.71 & 157.46 & 0.07 \\
ZG30 & 311.99 & 231.49 & 0.11 \\
ZG60 & 168.22 & 125.56 & 0.06 \\
ZG100 & 44.95 & 30.18 & 0.01
\end{tabular}

${ }^{\mathrm{a}}$ Surface area; ${ }^{\mathrm{b}}$ Micropore area; ${ }^{\mathrm{c}}$ Micropore volume.

As shown in Table 1, the BET surface area of all the ZT samples, measured by $\mathrm{N}_{2}$ adsorption, was around or larger than $350 \mathrm{~m}^{2} \mathrm{~g}^{-1}$, the ZB synthesis had small differences in the surface areas according to its SAR, ranging from 280 to 380 . ZSM-5 with lower SAR had larger surface areas since has particles with smaller size. The ZG30 synthesis gave high surface and micropore areas with a crystalline structure, close to the $\mathrm{ZT}$ and $\mathrm{ZB}$ structures produced from conventional and expensive routes. 


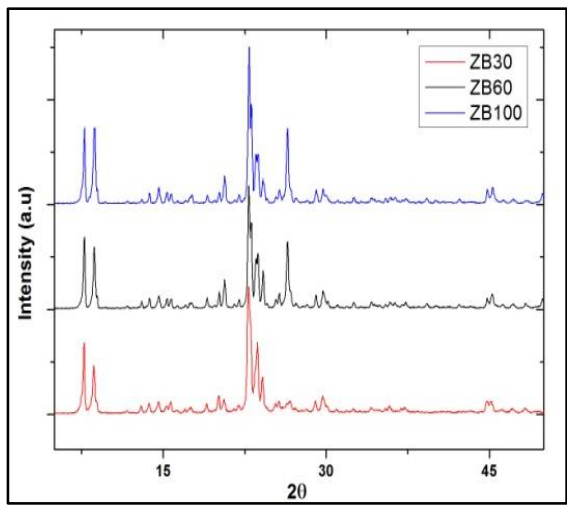

(a)

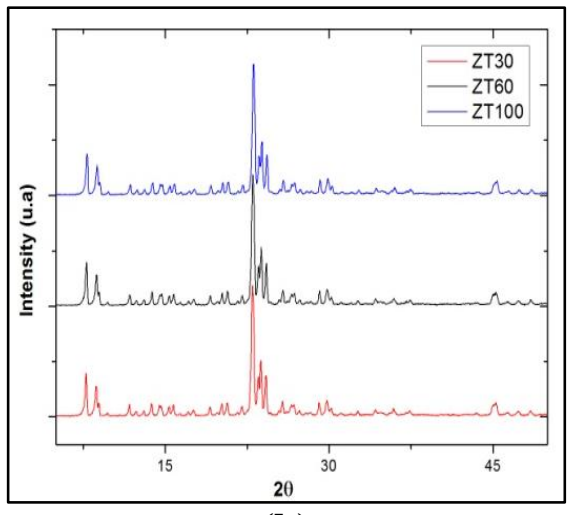

(b)

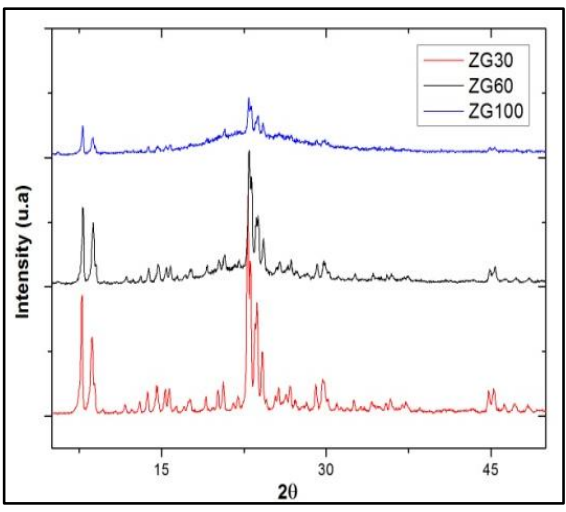

(c)

Figure 1 - XRD patterns for the different catalysts. a) ZB30, 60 and 100. b) ZT30, 60 and 100, c) ZG30, 60 and 100 .

The morphology from the ZSM-5 in its different templates at SAR 30 can be seen in the SEM images (Fig. 2). In all cases with a SAR value of 30, provides a well-defined structure with large surface area. In the SEM images different particle shapes were obtained, for the ZT30 was found more than one crystallization form (Fig. 2a), in the case of ZB30 was found aggregates in spherical forms (Fig. 2b) and for the ZG30, small particles with excellent structure and (Fig. 2c) great uniformity between them, that way proving once again to be a viable alternative to achieve welldefined ZSM-5 zeolites. The ZG30 generates a structure with large surface and micropore area (Table 1) in a synthesis were a small quantity of template is used in a short reaction time (12 h) and the SEM images showed that the ZG30 has a similar or superior structure compared with the two others traditional synthesis realized.

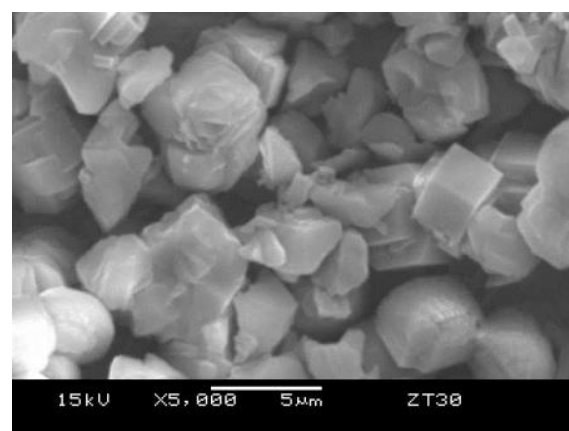

a)

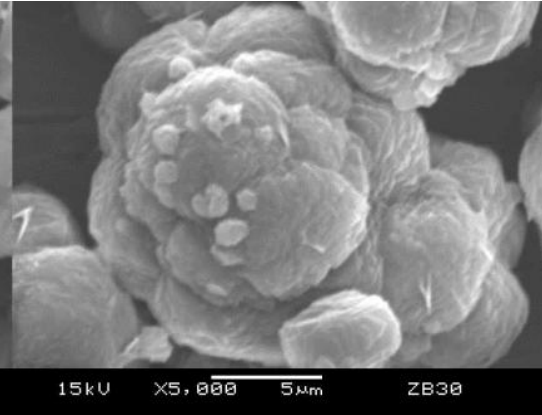

b)

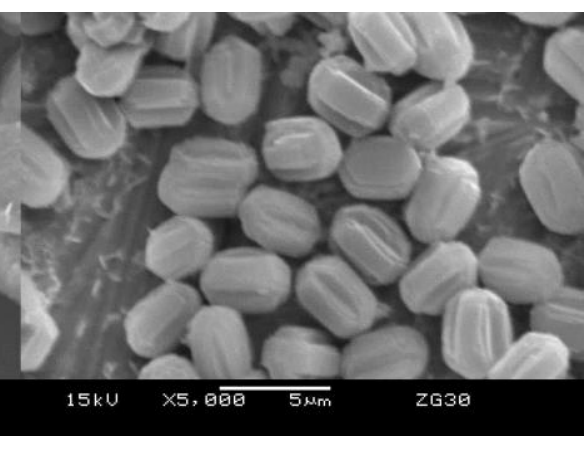

c)

Figure 2 -SEM images for the three different catalysts (SAR 30), a) ZT, b) ZB and c) ZG.

\subsection{Ethanol Conversion over HZSM-5}

The influence on the conversion of ethanol to light olefins for the different synthesized HZSM-5 was investigated; the influence of SAR and temperature was analyzed. In general, the temperature had a crucial role for the olefins formation, especially propylene. The reaction temperature studied ranged from 250 to $450{ }^{\circ} \mathrm{C}$, each analysis (in intervals of $50{ }^{\circ} \mathrm{C}$ ) was made after a 40 minutes contact 
between the ethanol flow and the catalyst. In our experiments, when increasing the temperature, the ethylene production was raised by the dehydration of ethanol (Fig. 3).

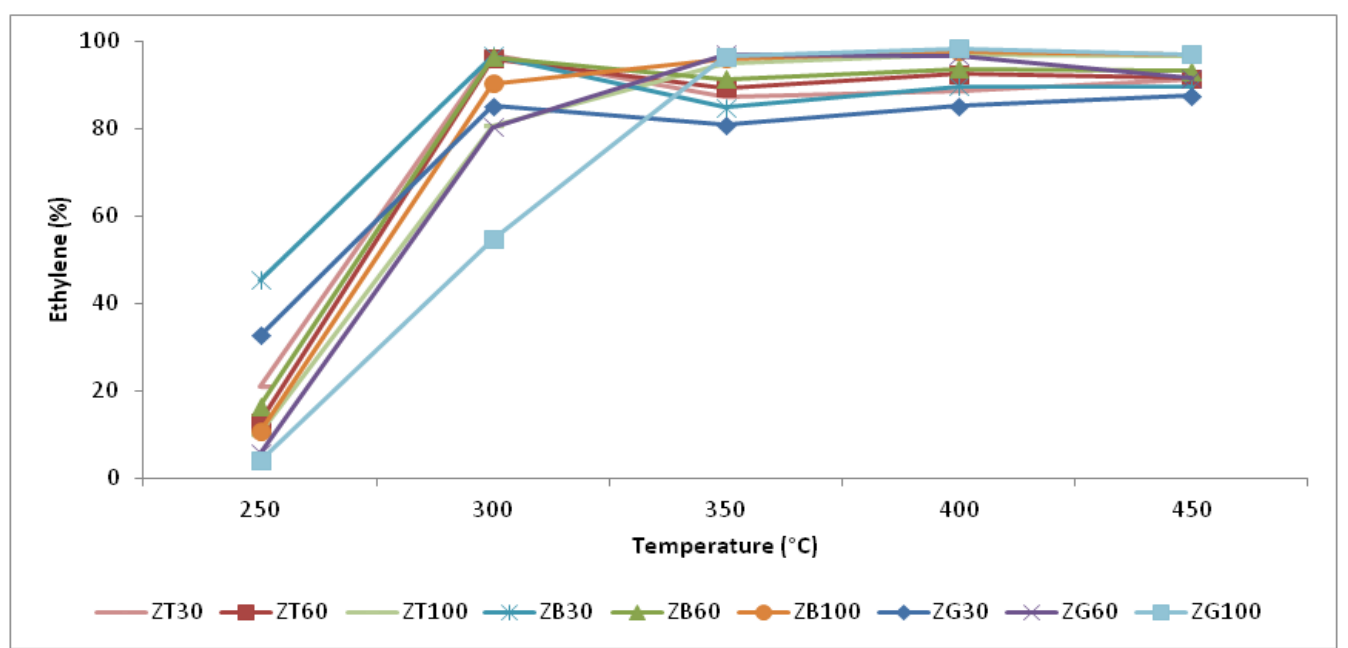

Figure 3 - Ethylene selectivity.

At lower temperatures, ethanol conversion was not $100 \%$ in all cases at $250{ }^{\circ} \mathrm{C}$ and in some at $300{ }^{\circ} \mathrm{C}$, showing formation of ether and ethylene. The reaction at $350{ }^{\circ} \mathrm{C}$ and above, in all catalysts, had $100 \%$ ethanol conversion and with the higher selectivity for propylene (Fig. 4). At $400{ }^{\circ} \mathrm{C}$ we found, in general, also a fine conversion for propylene, but it is notice a decrease in this selectivity, what continues at $450{ }^{\circ} \mathrm{C}$. As the cause of the change in the product selectivity, carbon deposition during reaction can be considered. The yield for ethylene was great for all catalyst at 350 and $400{ }^{\circ} \mathrm{C}$, with values above $80 \%$, even bigger for the catalyst at higher SAR values, up to $90 \%$ conversion.

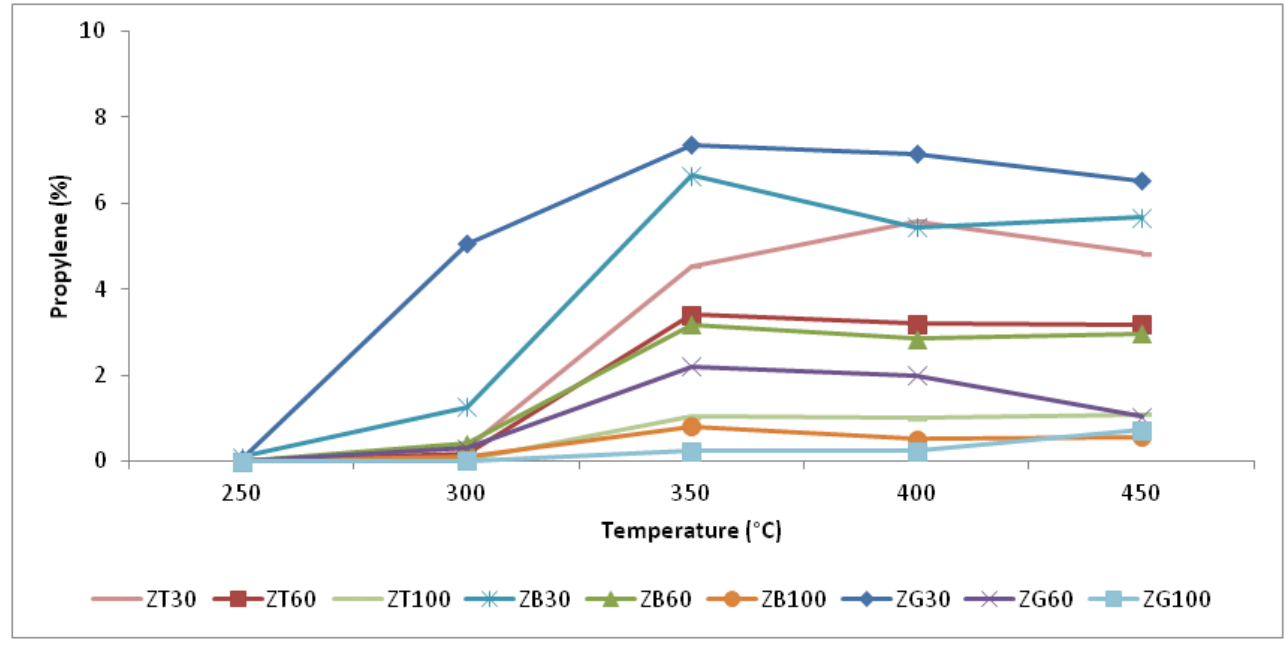

Figure 4 - Propylene selectivity.

At the same time that the temperature is an important factor in light olefins conversion, the SAR value also demonstrate to be an important factor for the ETO reaction. The solid acidic sites (Brønsted 


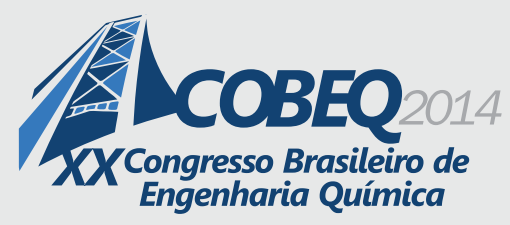

19 a 22 de outubro de 2014
Florianópolis/SC

acid) of the zeolite, essential for this reaction, are generated by $\mathrm{Al}$ atoms incorporated into the zeolite framework, since catalyst with shorter SAR value, had more aluminum in its structure is expected that a catalyst with SAR 30 will produce superior conversion for olefins compared with a major SAR. Figure 5 shows the dependence of SAR on all the HZSM-5 synthesized for propylene formation in the ideal temperature of $350{ }^{\circ} \mathrm{C}$. The catalyst synthesized, using nucleating gel (ZG), prove to be viable for the ETO reaction, especially for propylene formation, since was achieved conversions close to the two other traditional catalysts. In accordance with our results, Inoue et al. (2010) reported the highest propylene selectivity at SAR 29, and the selectivity decreased with higher $\mathrm{Si} / \mathrm{Al}_{2}$ ratio (weak surface acidity).

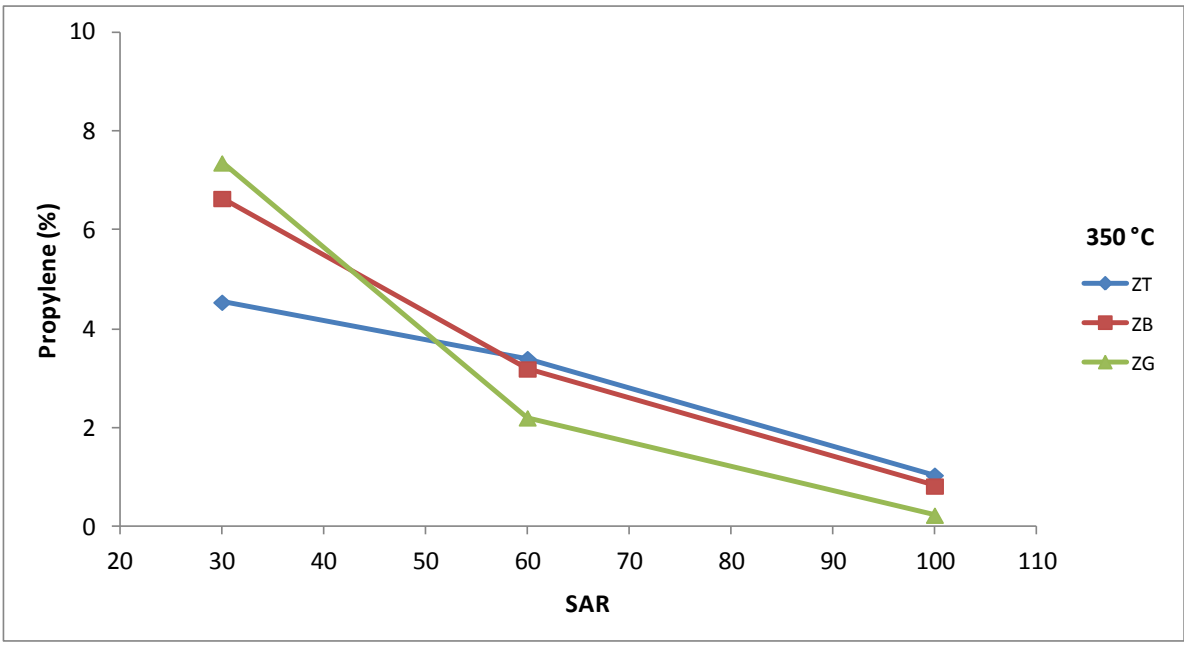

Figure 5 - Propylene conversion at different SAR values.

After the reaction from 250 to $450{ }^{\circ} \mathrm{C}$, the reaction oven was set to the ideal temperature of 350 ${ }^{\circ} \mathrm{C}$ and another analysis was made to evaluate the catalyst deactivation. At this point was notice a strong decrease in the propylene yield, from the early almost $8 \%$ to around $1 \%$. The probable cause of this result is the carbon deposition during reaction, in view of that, the catalyst was maintained for $8 \mathrm{~h}$ on synthetic air at $500{ }^{\circ} \mathrm{C}$, and another analysis was carried out after that process. The selectivity for propylene enhanced to around $2.5 \%$, improving the result, but not recovering the same activity from the beginning.

\section{CONCLUSIONS}

Two ZSM-5 synthesis methods, using traditional templates and an alternative way using a nucleating gel with low concentration of template have been synthesized. ZSM-5 was easily obtained in the nucleating gel method (ZG), at short reaction time in an inexpensive synthesis, generating at SAR 30 (ZG30) a well-defined structure with high crystallinity and surface area. The catalytic conversion of ethanol was performed by using the HZSM-5 synthesized in the three different methods, with SAR from 30 to 100, and the catalysts were efficient for ethanol conversion to light olefins. The results for ethylene were higher than $80 \%$ in all cases with some of them above to $90 \%$, for propylene the results were satisfactory. However, in general, the selectivity of propylene was slightly decreased with time-on-stream when increasing the temperature. The ideal temperature was 
$350{ }^{\circ} \mathrm{C}$ for all catalysts. The probable cause of these results is the carbon deposition on the catalyst. The catalyst ZG 30 gave great results in its synthesis and in the catalytic activity compared with the catalysts synthesized in traditional routes (ZT and ZB), proving its high cost-benefit.

\section{REFERENCES}

ARGAUER, R.J.; LANDOLT, G.R. Crystalline zeolite ZSM-5 and method of preparing the same. U.S. Pat. 3,702, 886, 1972.

CHENG Y.; LIAO R.H.; LI J.S.; SUN X.Y.; WANG L.J. Synthesis research of nanosized ZSM-5 zeolites in the absence of organic template. J. Mater. Process. Technol., 206, 445-452, 2008.

FOUAD O.A.; MOHAMED R.M.; HASSAN M.S.; IBRAHIM I.A. Effect of template type and template/silica mole ratio on the crystallinity of synthesized nanosized ZSM-5. Catal. Today., 116, 82-87, 2006.

INABA M.; MURATA K.; SAITO M.; TAKAHARA I. Production of olefins from ethanol by Fesupported zeolite catalysts. Green Chem., 9, 638-646, 2007.

INOUE K.; INABA M.; TAKAHARA I.; MURATA K. Conversion of Ethanol to Propylene by HZSM-5 with Si/A12Ratio of 280. Catal. Lett. 136:14-19, 2010.

KALIPÇILAR H.; ÇULFAZ A. Template-Free Synthesis of ZSM-5 Type Zeolite Layers on Porous Alumina Disks. Turk. J. Chem., 31, 233-242, 2007.

LAM, Y. L. Nucleating Gel, Process for its preparation, and its use in the synthesis of MFI-TYPE Zeolite. C01B 39/40, C01B 39/04. n WO2006-087337, 2006.

LU J.; LIU Y. Effects of $\mathrm{P}$ content in a P/HZSM-5 catalyst on the conversion of ethanol to hydrocarbons. J. Nat. Gas Chem., 20, 162-166, 2011.

MENG T.; MAO D.; GUO Q.; LU G. The effect of crystal sizes of HZSM-5 zeolites in ethanol conversion to propylene. Catal. Commun., 21, 52-57, 2012.

OUYANG J.; KONG F.; SU G.; HU Y.; SONG Q. Catalytic conversion of bio-ethanol to ethylene over La-modified HZSM-5 catalysts in a bioreactor. Catal Lett., v. 132, p. 64-74, 2009.

RUBIN, M. K.; ROSINKI, E. J.; PLANCK, C. J. Synthezing Low Sodium Crystalline Aluminosilicate Zeolites with Primary Amines. U.S. Pat. 4, p.151-189, 1979.

SANG S.; CHANG F.; LIU Z.; HE C.; HE Y.; XU L. Difference of ZSM-5 zeolites synthesized with various templates. Catal. Today., 93-95, 729-734, 2004. 